\title{
Determinantes da Massa Óssea do Esqueleto Total em Mulheres Pré-menopáusicas de Porto
}

\section{Alegre: Um Estudo de Base Populacional}

Autora: Sylvia Villar Mello Guimarães

Orientadores: Profa. Dra. Sandra Costa Fuchs e Dr. José Augusto Sisson de Castro

Dissertação de Mestrado apresentada à Universidade Federal do Rio Grande do Sul para obtenção do grau de Mestre em Medicina: Endocrinologia, em 21 de dezembro de 2001.

Objetivo: Avaliar a associação entre raça e densidade mineral óssea de uma amostra populacional de mulheres na pré-menopausa de Porto Alegre.

Métodos: Amostra representativa de 158 mulheres com idade entre 25 e 45 anos residentes em Porto Alegre, RS, Brasil. Entrevistadores treinados aplicaram questionários padronizados, pré-testados e pré-codificados para estudar as características demográficas, socioeconômicas e hábitos comportamentais que associamse à densidade mineral óssea. A raça foi determinada pela observação da cor da pele por entrevistador treinado e pelo número de ancestrais da raça negra. A densitometria óssea de corpo total (DMOT), por absormetria de Raio-X duo-energético (DXA) foi realizada no Hospital das Clínicas de Porto Alegre.

Resultados: 105 mulheres que não apresentaram ancestrais da raça negra foram classificadas como brancas, 13 mulheres com um a dois ancestrais negros, como mistas e 40 mulheres com três ou mais ancestrais da raça negra, como negras. Uma associação significativa $(\mathrm{p}<0,05)$ foi encontrada entre a DMOT e o número de ancestrais da raça negra, ingestão de cálcio < $300 \mathrm{mg} /$ dia, altura, renda familiar per capita e consumo de bebidas alcoólicas. O conteúdo mineral ósseo total (CMOT) associou-se significativamente $(\mathrm{p}<0,05)$ somente com o número de ancestrais da raça negra, altura e peso. Na análise multivariada observamos que a altura, ingestão de cálcio, atividade física e número de ancestrais negros associaram-se com a DMOT de maneira significativa e independente. A associação das mesmas características com o CMOT, exceto o cálcio, também foram independentes e significativas. Estas variáveis explicaram 21,3\% e 40,0\% das diferenças de DMOT e CMOT, respectivamente. $\mathrm{Na}$ comparação entre os grupos divididos pelo número de ancestrais da raça negra as diferenças entre as médias de DMOT e CMOT entre brancas e negras foram significativas $(p=0,0013)$, não havendo outras diferenças entre os três grupos.

Conclusão: A raça identificada pelo número de ancestrais é o principal determinante da massa óssea medida pelo DMOT ou CMOT.

Palavras-chave: Massa óssea. Densitometria. Menopausa. Menacme.

\section{Estudo Longitudinal de Variáveis Dopplervelocimétricas do Ducto Venoso Fetal em Gestações Normais}

Autora: Alessandra Cristina Marcolin

Orientador: Prof. Dr.Geraldo Duarte

Dissertação de Mestrado apresentada à Faculdade de Medicina de Ribeirão Preto da Universidade de São Paulo, para obtenção do título de Mestre em Medicina. Área de Concentração: Tocoginecologia, em 10 de dezembro de 2001.

Introdução: O ducto venoso (DV) é uma continuação da porção intra-abdominal da veia umbilical capaz de transportar sangue altamente oxigenado diretamente da placenta para o coração fetal, evitando que grande parte desse fluxo passe pela circulação hepática. Por meio deste "shunt", o sangue rico em nutrientes alcança o coração do feto, permitindo sua sobrevivência em situações de estresse. Estudos da circulação venosa fetal, com o método Doppler, têm demonstrado a importância do DV na avaliação do bem-estar do feto. Objetivos: Analisar qualitativamente as características das ondas de velocidade de fluxo no DV e estabelecer curvas de normalidade dos valores das variáveis dopplervelocimétricas, assim como suas variações fisiológicas ao longo da segunda metade da gestação em gestantes normais.

Métodos: Estudo longitudinal envolvendo 51 gestantes saudáveis sem patologias fetais, utilizando ultra-sonografia com Doppler, durante a segunda metade da gestação. Foram registradas ondas de velocidade de fluxo do DV fetal, possibilitando o cálculo da velocidade de fluxo do pico sistólico (VPS), velocidade de fluxo do pico diastólico (VPD), velocidade de fluxo durante a contração atrial (VCA), relação entre pico sistólico/contração atrial (S/A ratio), do índice de pulsatilidade para veias (IP), índice de pré-carga (IPC) e índice de velo- 
cidade para veias (IVV). Essas aferições foram repetidas a cada quatro semanas. A distribuição normal das variáveis estudadas foi confirmada com o teste de Kolmogorov-Smirnoff, permitindo a utilização de testes paramétricos na análise estatística dos dados.

Resultados: Observou-se aumento progressivo e estatisticamente significativo da VPS, da VPD e da VCA da $20^{\mathrm{a}}$ até a $28^{\mathrm{a}}$ semana de gestação, havendo estabilização dos valores dessas variáveis até o final da gravidez. Por outro lado, houve redução progressiva e estatisticamente significativa da S/A ratio, do IP, do IPC e do IVV da $20^{a}$ à $28^{a}$ semana de gestação com estabilização dos valores dessas variáveis até o termo. Com esses resultados foi possivel construir curvas de normalidade de todas as variáveis estudadas.
Conclusões: Este estudo mostrou como variáveis dopplervelocimétricas do DV variam ao longo da segunda metade da gravidez normal. Diversos fatores podem estar envolvidos nos aumentos das velocidades de fluxo e reduções dos índices no DV, tais como aumento do volume do fluxo, redução do gradiente de pressão entre os átrios e ventrículos fetais, resultando em elevação da complacência cardiaca ao longo da gravidez e queda fisiológica das resistências periférica e placentária, com conseqüente melhora da função miocárdica e redução da pré-carga, notadamente após a $26^{\circ}$ semana.

Palavras-chave: Ducto venoso. Gestação normal. Dopplervelocimetria. Bem-estar fetal.

\section{Repercussões de Técnicas Fisioterápicas Aplicadas no Programa Multidisciplinar de Preparo para 0 Parto e Maternidade sobre os Desconfortos Músculo-Esqueléticos da Gestação}

Autora: Marta Helena Souza de Conti

Orientadora: Iracema de Mattos Paranhos Calderon

Dissertação Apresentada ao Curso de Pós-Graduação em Ginecologia e Obstetrícia, Área de Concentração Obstetrícia, na Faculdade de Medicina de Botucatu - Unesp, para a obtenção do Título de Mestre, em 25 de fevereiro de 2002.

Objetivo: Estudar os efeitos de técnicas fisioterápicas, aplicadas no Programa Multidisciplinar de Preparo para o Parto e Maternidade (PMPMa), sobre os desconfortos músculo-esqueléticos na gestação.

Sujeitos e Método: Coorte prospectivo, com 71 gestantes nuliparas, de baixo risco, distribuídas conforme a participação (Estudo; n=38) ou não (Controle; n=33) no PMPMa. Este programa teve 10 encontros $\left(18^{a}\right.$ a $38^{a}$ semanas), com atividades educativas, fisioterápicas e de interação. Comparou-se, por questionário específico, no início e final do PMPMa, a ocorrência, as características e a evolução dos desconfortos músculo-esqueléticos. Resultados: No início do PMPMa, 63,6\% das gestantes do grupo Controle e $84,2 \%$ do Estudo relataram sintomas músculo-esqueléticos $(\mathrm{p}=0,05)$, caracterizados por dor na região lombossacra. No Controle predominaram a intensidade leve $(18,2 \%)$ e grave $(18,4 \%)$ e, no
Estudo, a grave $(36,8 \%)$, isolada ou associada $(31,6 \%)$. No final, o Controle tinha sintomas de intensidade grave $(60,6 \%)$, com freqüência diária $(42,4 \%)$ e duração maior que três horas $(69,7 \%)(p<0,05)$. O Estudo referia intensidade leve $(57,9 \%)$ e freqüência quinzenal $(50,0 \%)$ com duração máxima de uma hora $(55,3 \%)$ $(\mathrm{p}<0,05)$. A evolução dos sintomas também foi diferenciada, confirmando-se piora em $63,6 \%$ das gestantes do Controle e melhora em $65,8 \%$ das participantes do PMPMa $(\mathrm{p}<0,05)$.

Conclusões: As atividades fisioterápicas do PMPMa se relacionaram à diminuição da intensidade, freqüência e duração e à melhor evolução dos desconfortos músculo-esqueléticos na gestação.

Palavras-chave: Gravidez normal. Pré-natal. Fisioterapia. em Gestantes com Diabetes Mellitus

Autora: Rosy Ane de Jesus Pereira Araújo Barros

Orientador: Profa ${ }^{a}$. Dra. Anna Maria Bertini

Co-orientador: Dr. Wladimir Taborda

Tese de Mestrado apresentada ao Departamento de Obstetrícia da Universidade Federal de São Paulo - Escola Paulista de Medicina para obtenção do Título de Mestre em Obstetrícia, em 13 de dezembro de 2001.

Objetivo: Avaliar o desempenho da dopplerfluxometria das artérias uterinas, umbilicais e cerebrais médias no curso da gestação de diabéticas.

Pacientes e Método: Foram incluídas 32 gestantes dia- 
béticas, que fizeram uso de insulina para o controle glicêmico. Foi estudada a evolução dos índices de resistências ao longo da gestação e correlacionado a complicações maternas e perinatais.

Resultados: A incisura bilateral nas artérias uterina teve acurácia similar para as complicações maternas (pré-eclâmpsia e parto pré-termo). A sensibilidade foi $40 \%$ e $38 \%$; especificidade de $85 \%$ e $88 \%$; VPP de $33 \%$ e $50 \%$ e VPN foi de $88 \%$ e $80 \%$, respectivamente. Para os eventos perinatais foram utilizadas as artérias umbilicais, cerebrais médias e a ocorrência de centralização de fluxo sangüineo. As artérias umbilicais demonstraram baixa sensibilidade (33\%, 0\% e 25\%) e VPP (33\%, 0\% e 17\%); e valores mais elevados de especificidade (85\%, $77 \%$ e $82 \%$ ) e o VPN (85\%, $77 \%$ e $88 \%)$. As artérias cerebrais médias apresentaram sensibilidade (67\%, 50\% e $75 \%)$, especificidade (80\%, 77\% e $78 \%$ ) e
VPN (91\%, 87\% e 95\%) melhores para detectar os eventos perinatais, no entanto, com baixo VPP (44\%, 33\% e $33 \%)$. A centralização do fluxo sangüineo fetal revelou baixa sensibilidade (33\%, 17\% e 25\%) e VPP $(50 \%$, $25 \%$ e $25 \%$ ), com elevada especificidade (92\%, $88 \%$ e $89 \%)$ e VPN (85\%, $82 \%$ e $89 \%)$.

Conclusão: A dopplerfluxometria das artérias uterinas foi considerado um método satisfatório para predizer a ausência de pré-eclâmpsia e parto pré-termo. A dopplerfluxometria das artérias umbilicais e cerebrais médias demonstrou ser um bom método para predizer a ausência de complicações neonatais como baixo peso ao nascer, policitemia e ingresso em UTI.

Palavras-chave: Diabete melito. Complicações da gravidez. Prematuridade. Hipertensão. Dopplervelocimetria.

\begin{tabular}{ll}
$\mathrm{RBCO}$ & $24(4): 279,2002$ \\
\hline
\end{tabular}

Resumos de Tese

\section{Punção Aspirativa por Agulha Fina: Estudo Comparativo entre Dois Diferentes Dispositivos para a Obtenção da Amostra Citológica}

Autor: Ruffo de Freitas Júnior

Orientador: Prof. Dr. Gustavo Antonio de Souza

Co-Orientadora: Prof ${ }^{\mathrm{a}}$. Dr ${ }^{\mathrm{a}}$. Ellen Elizabeth Hardy

Tese de Doutorado apresentada à Pós-Graduação da Faculdade de Ciências Médicas da Universidade Estadual de Campinas para obtenção do Título de Doutor em Tocoginecologia, área de Tocoginecologia, em

A punção aspirativa por agulha fina (PAAF) tem sido mundialmente aceita na abordagem das lesões mamárias. Porém, alguns pontos ainda são controversos. Entre eles, está o método de punção a ser utilizado. Objetivo: Comparar os aspirados gerados pelo dispositivo de autovácuo com os da pistola de apreensão de seringa, através de citometria de fluxo e de citologia oncológica.

Sujeitos e Métodos: O estudo foi dividido em duas partes distintas, sendo a primeira um ensaio em que a punção era realizada por ambos os métodos, na peça cirúrgica fresca, contendo tumor de mama ex vivo. Para a segunda parte foi conduzido um estudo randomizado, onde pacientes com nódulos mamários eram submetidas à PAAF, utilizando-se a pistola de apreensão ou o dispositivo de autovácuo in vivo. No estudo ex vivo, foram utilizadas 44 peças frescas, contendo tumores mamários. Em cada, peça procedeu-se a PAAF por ambas as técnicas. Posteriormente as mesmas foram fixadas e incluidas em parafina. Tanto os aspirados quanto o material histológico desparafinizado foram preparados para citometria de fluxo. Utilizou-se um aparelho BD FACScan, com leitura de 10.000 células por exame. Para o estudo in vivo, 380 pacientes com nódulos sólidos na mama foram submetidas à PAAF utilizando-se um dos dispositivos de punção, de forma aleatória. A leitura citológica foi feita por um único observador, sendo que
29 casos não foram vistos por ele e excluídos da análise. Posteriormente, 295 pacientes tiveram seus tumores ressecados. Para os 273 casos remanescentes analisou-se a acurácia para cada método, além da taxa de material insuficiente, celularidade, distorção celular e hemorragia de fundo.

Resultados: No estudo ex vivo, a citometria de fluxo mostrou que as médias do coeficiente de variação, do indice de DNA, da fase-S e da aneuploidia, foram semelhantes entre os aspirados da pistola e do autovácuo. A média de células aneuploides foi significativamente maior nos aspirados do autovácuo do que na peça cirúrgica $(43,4 \mathrm{DP} \pm 23$ vs $27,9 \mathrm{DP} \pm 17 ; \mathrm{p}=0,04)$. No estudo in vivo, a taxa de material insuficiente foi de $16 \%$ e $22 \%$ (NS) para os aspirados do autovácuo e da pistola, respectivamente. A sensibilidade absoluta foi de $63 \%$ e 58\%; a especificidade de $77 \%$ e $78 \%$ e a acurácia total de $76 \%$ e $75 \%$, para o autovácuo e para a pistola, respectivamente. A celularidade, a distorção celular e o fundo hemorrágico também foram semelhantes entre os dois métodos. Conclusão: Os dois métodos de punção foram equivalentes para estudo de citometria de fluxo e citologia oncológica.

Palavras-chave: Câncer de mama. Punção por agulha. Mama: câncer, diagnóstico. Citologia. 